Jurnal Ilmu Ilmu Agribisnis: Journal of Agribusiness Science, 9(3), Agustus 2021

\title{
KINERJA PRODUKSI DAN KEBERLANJUTAN AGROINDUSTRI EMPING MELINJO DI KECAMATAN TAKTAKAN KOTA SERANG
}

\author{
(Production Perfomance and Sustainability of Emping Melinjo Agroindustry \\ in Taktakan Subdistrict of Serang City)
}

Shelma Anantapuri, Adia Nugraha, Wuryaningsih Dwi Sayekti

Jurusan Agribisnis, Fakultas Pertanian, Universitas Lampung, Jl. Prof. Dr. Soemantri Brodjonegoro No. 1 Bandar Lampung 35145, e-mail: adia.nugraha@fp.unila.ac.id

\begin{abstract}
This research aimed to analyze procurement of raw materials, production perfomance, fixing cost of goods sold, application of marketing mix, and the sustainability of emping melinjo agroindustry. The location of this research was chosen purposively in Taktakan Subdistrict Serang City in which samples were all of three emping melinjo Agroindustries. The data of this research was primary and secondary data that was collected in March - April 2019. The methods of data analysis used in this research were descriptive, qualitative and quantitative analyses. The results of this research showed that procurement of melinjo raw materials had not appropriate with the six right criteria which were right on time, place, quality, quantity, type, and price. Production performance of emping melinjo agroindustry was quite good although the flexibility component had not been fulfilled yet. Fixing cost of goods sold of emping melinjo agroindustry had been profitable. Application of marketing mix had been implemented quite well although it needs to be improved in several aspects such as promotion. The sustainability of emping melinjo agroindustry in Taktakan Subdistrict Serang City has a good prospect.
\end{abstract}

Key words: agroindustry, emping melinjo, perfomance, sustainability

\section{PENDAHULUAN}

Agroindustri yang telah dikembangkan di Indonesia cukup beragam sesuai dengan potensi sumberdaya yang terdapat pada daerah tersebut salah satu contoh di Provinsi Banten memiliki beragam industri yang bergerak di bidang pertanian. Beberapa agroindustri yang ada di Provinsi Banten, misalnya industri olahan berbahan dasar hasil-hasil pertanian seperti, melinjo, jagung, bandeng presto, singkong, dan lain sebagainya. Beberapa makanan olahan tersebut telah menjadi makanan khas dari Provinsi Banten, yang kini semakin banyak diminati oleh masyarakat maupun wisatawan yang datang ke Provinsi Banten.

Salah satu produk pengolahan hasil pertanian yang dikenal di Provinsi Banten adalah emping melinjo. Tanaman melinjo sebagai bahan baku emping melinjo merupakan salah satu subsektor perkebunan yang dinilai cukup strategis dalam mendukung perekonomian daerah. Emping melinjo sendiri merupakan komoditas agroindustri yang potensial dan berprospek cukup cerah dalam menunjang perekonomian. Tanaman melinjo merupakan tanaman unggulan Provinsi Banten, karena memiliki produksi kedua tertinggi setelah komoditas pisang yaitu sebesar 348.745 ton pada tahun 2016 (Dinas Pertanian Tanaman Pangan dan Hortikultura Provinsi Banten 2017).

Agroindustri emping melinjo banyak dikembangkan di Provinsi Banten, salah satunya di Kecamatan Taktakan Kota Serang karena memiliki potensi ketersediaan bahan baku yang cukup tinggi. Namun kenyataannya agroindustri emping melinjo di Kecamatan Taktakan Kota Serang mengalami kemunduran, karena banyak agroindustri emping melinjo yang berhenti beroperasi, tidak dapat bersaing dengan produk agroindustri skala mikro lainnya dan adanya permasalahan bahan baku melinjo yang semakin menurun. Hal tersebut terjadi karena tanaman melinjo tidak dibudidayakan secara khusus oleh petani dan merupakan tanaman turun menurun yang saat ini sudah banyak beralih fungsi menjadi perumahan, jalan raya, dan lain-lain. Dalam jangka panjang diduga akan terjadi kekurangan bahan baku yang secara langsung akan berdampak pada keberlanjutan bagi agroindustri emping melinjo.

Saat ini hanya tiga agroindustri emping melinjo yang masih aktif beroperasi di Kecamatan Taktakan Kota Serang antara lain Agroindustri 
Kosim, Agroindustri Robiah, dan Agroindustri Mulyati (Dinas Perindustrian Perdagangan dan Koperasi Kota Serang 2018). Permasalahan yang sering dihadapi oleh pelaku agroindustri di Kecamatan Taktakan Kota Serang adalah harga bahan baku yang fluktuatif akibat ketersediaan bahan baku yang fluktuatif pula. Menurut hasil wawancara dengan salah satu pemilik Agroindustri emping melinjo menyatakan bahwa pada tahun 2017 harga melinjo mengalami kenaikan harga yaitu sebesar Rp16.000/kg, sedangkan normalnya harga melinjo Rp12.000/kg. Selain harga bahan baku, persediaan bahan baku yang selalu tersedia dan cukup, sangat diperlukan dalam pengolahan emping pada agroindustri emping melinjo.

Kegiatan pengolahan merupakan kegiatan menciptakan produk. Apabila kegiatan pengolahan bahan baku dilakukan dengan baik, maka menghasilkan produksi berkualitas tinggi. Hal ini mengakibatkan kinerja produksi menjadi salah satu faktor pendukung dalam perkembangan dari ketiga agroindustri emping melinjo yang ada di Kecamatan Taktakan Kota Serang. Ketiga agroindustri tersebut selama ini belum melakukan perhitungan harga pokok produksi, hanya menghitung biaya-biaya yang membutuhkan pengeluaran tunai.

Penentuan harga pokok produksi sangat penting dalam penentuan harga jual. Selain kegiatan produksi, kegiatan pemasaran adalah salah satu aspek penting yang perlu diperhatikan pada kegiatan suatu usaha. Permasalahan yang timbul pada tiga agroindustri adalah wilayah pemasaran yang masih tergolong sempit. Pemasaran yang dilakukan oleh agroindustri emping melinjo hanya di wilayah Kota Serang saja. Tujuan penelitian ini adalah untuk menganalisis pengadaan bahan baku, kinerja produksi, penetapan harga pokok produksi, penerapan bauran pemasaran, dan menganalisis keberlanjutan agroindustri emping melinjo di Kecamatan Taktakan, Kota Serang.

\section{METODE PENELITIAN}

Penelitian ini dilakukan dengan menggunakan metode sensus. Lokasi penelitian dipilih secara sengaja (purposive), yaitu pada tiga lokasi industri yaitu Agroindustri Kosim, Agroindustri Robiah dan Agroindustri Mulyati yang berada di Kecamatan Taktakan Kota Serang. Menurut Arikunto (2002), apabila subjek penelitian kurang dari 100 lebih baik diambil semua, sehingga penelitian merupakan penelitian populasi.
Data yang digunakan dalam penelitian ini adalah data primer dan data sekunder. Data primer diperoleh melalui pengamatan secara langsung dan wawancara dengan pemilik agroindustri emping melinjo di Kecamatan Taktakan Kota Serang menggunakan kuesioner yang telah disediakan. Data primer meliputi jumlah produksi, jumlah tenaga kerja, frekuensi pembelian bahan baku, jenis bahan baku yang digunakan dan tempat pemasaran produk emping. Data sekunder diperoleh dari lembaga terkait yang berhubungan dengan objek penelitian, diantaranya, Dinas Perindustrian Perdagangan dan Koperasi, Badan Pusat Statistik dan literatur lainnya yang berkaitan dengan topik penelitian.

Metode analisis deskriptif kuantitatif digunakan untuk mejawab tujuan penelitian pertama mengenai proses pengadaan bahan baku yang menggunakan enam tepat pada agroindustri emping melinjo. Enam tepat tersebut adalah tepat waktu, tepat tempat, tepat jenis, tepat kualitas, tepat kuantitas, dan tepat harga (Assauri 1999). Analisis enam tepat juga digunakan oleh Shafira, Lestari dan Affandi (2018) yang menggunakan enam indikator untuk menganalisis pengadaan bahan baku.

Analisis kinerja produksi dilakukan untuk melihat hasil kerja dari agroindustri emping melinjo dengan menggunakan empat indikator yaitu produktivitas, kapasitas, kualitas, dan kecepatan pengiriman. Analisis kinerja produksi juga digunakan oleh Putri, Haryono, dan Nugraha (2019) yang menggunakan empat indikator untuk menganalisis kinerja produksi.

Produktivitas dari agroindustri dihitung dari unit yang diproduksi (output) dengan masukan yang digunakan (tenaga kerja) yang dirumuskan sebagai berikut.

Produktivitas $=\frac{\text { Unit yang diprodulksi (kg) }}{\text { Masukan yang digunakan (HOK: }}$

Kapasitas yaitu suatu ukuran yang menyangkut kemampuan output dari suatu proses. Kapasitas agroindustri diperoleh dari actual output yaitu output berupa emping melinjo yang diproduksi dengan satuan $\mathrm{kg}$ dan design capacity yaitu kapasitas maksimal memproduksi emping melinjo dengan satuan $\mathrm{kg}$. Kapasitas agroindustri dapat dirumuskan sebagai berikut :

Capacity Utilization $=\frac{\text { Actual output }(\mathrm{kg})}{\text { Design capacity }(\mathrm{kgg})}$. 
Tabel 1. Syarat mutu emping melinjo berdasarkan SNI-01-3712-1995

\begin{tabular}{|c|c|c|}
\hline Uraian & Satuan & Syarat Mutu \\
\hline \multicolumn{3}{|l|}{ 1. Keadaan } \\
\hline - Bau & - & Khas melinjo \\
\hline - Rasa & - & Khas melinjo \\
\hline - Warna & - & Normal \\
\hline - Penampakan & - & $\begin{array}{l}\text { Normal, bersih dari } \\
\text { kulit ari yang } \\
\text { menempel dan } \\
\text { benda asing } \\
\text { lainnya }\end{array}$ \\
\hline $\begin{array}{l}\text { 2. Emping tidak } \\
\text { Utuh }\end{array}$ & $\%, \mathrm{~b} / \mathrm{b}$ & Maksimum 5 \\
\hline 3. Air & $\%, b / b$ & Maksimum 12 \\
\hline 4. $\mathrm{Abu}$ & $\%, \mathrm{~b} / \mathrm{b}$ & Maksimum 2 \\
\hline 5. Protein & $\%, \mathrm{~b} / \mathrm{b}$ & Maksimum 10 \\
\hline \multicolumn{3}{|l|}{$\begin{array}{l}\text { 6. Cemaran } \\
\text { logam }\end{array}$} \\
\hline$-\mathrm{Cu}$ & $\mathrm{mg} / \mathrm{kg}$ & Maksimum $=30$ \\
\hline$-\mathrm{PB}$ & $\mathrm{mg} / \mathrm{kg}$ & Maksimum $=2$ \\
\hline$-\mathrm{Hg}$ & $\mathrm{mg} / \mathrm{kg}$ & Maksimum $=0,03$ \\
\hline$-\mathrm{Zn}$ & $\mathrm{mg} / \mathrm{kg}$ & Maksimum $=40$ \\
\hline $\begin{array}{l}\text { 7. Cemaran } \\
\text { Arsen (As) }\end{array}$ & $\mathrm{mg} / \mathrm{kg}$ & Maksimum $=1$ \\
\hline $\begin{array}{l}\text { 8. Cemaran } \\
\text { mikroba } \\
\text { - kapang }\end{array}$ & Koloni/kg & Maksimum $=10^{4}$ \\
\hline
\end{tabular}

Kualitas dari proses pada umumnya diukur dengan tingkat ketidaksesuaian dari produk yang dihasilkan. Mutu emping melinjo dapat dinilai dengan menggunakan parameter-parameter baik terhadap sifat yang dapat dilihat seperti, keutuhan, keragaman pencetakan, nilai gizi dan rasa. Standar emping melinjo yang berlaku di Indonesia adalah standar mutu yang dikeluarkan Departemen Perindustrian dan Perdagangan tahun 1995, seperti terlihat pada Tabel 1.

Kecepatan pengiriman ada dua ukuran dimensi, pengukuran yang pertama yaitu jumlah waktu antara produk ketika dipesan untuk dikirimkan kepada pelanggan, pengukuran yang kedua adalah dengan melihat variabilitas dalam waktu pengiriman. Penentuan harga pokok produksi pada penelitian ini menggunakan metode variable coasting. Metode variable coasting hanya memperhitungkan biaya-biaya yang bersifat variable ke dalam harga pokok produksi, yang terdiri dari biaya bahan baku, biaya tenaga kerja, dan biaya overhead pabrik, dengan demikian harga pokok produksi menurut metode variable costing terdiri dari unsur biaya produksi seperti yang disajikan pada Tabel 2.
Tabel 2. Harga pokok produksi menggunakan metode variable costing

\begin{tabular}{|c|c|c|}
\hline Jumlah Produksi per bulan & & $\operatorname{xxx}(\mathrm{A})$ \\
\hline Biaya Bahan Baku & $\operatorname{xxx}(\mathrm{B})$ & \\
\hline Biaya Tenaga Kerja & $\operatorname{xxx}(C)$ & \\
\hline BOP Variabel & $\operatorname{xxx}(\mathrm{D})$ & \\
\hline $\begin{array}{l}\text { Total Harga Pokok Produksi } \\
(\mathrm{B}+\mathrm{C}+\mathrm{D})\end{array}$ & & $\operatorname{xxx}(\mathrm{E})$ \\
\hline $\begin{array}{l}\text { Harga Pokok Produksi per } \\
\mathrm{kg} \text { (E/A) }\end{array}$ & & $\operatorname{xxx}(F)$ \\
\hline
\end{tabular}

Penerapan bauran berupa $4 \mathrm{P}$ (Price, Place, Product, dan Promotion) digunakan untuk mengetahui bagaimana penerapan bauran pemasaran yang dilaksanakan di agroindustri. Analisis bauran pemasaran juga digunakan oleh Ledy, Haryono, dan Situmorang (2019), analisis bauran pemasaran digunakan untuk menghasilkan keuntungan yang maksimal. Informasi yang diperoleh ketika wawancara dengan menggunakan kuesioner dijabarkan secara rinci. Analisis ini bertujuan untuk mengetahui faktor-faktor internal dan eksternal yang berpengaruh terhadap keberlanjutan agroindustri emping melinjo di Kecamatan Taktakan Kota Serang.

\section{HASIL DAN PEMBAHASAN}

\section{Karakteristik Responden}

Responden dalam penelitian ini merupakan pemilik agroindustri emping melinjo yang terdapat di Kecamatan Taktakan Kota Serang yang terdiri dari Agroindustri Kosim, Agroindustri Robiah dan Agroindustri Mulyati. Seluruh pemilik agroindustri emping melinjo di Kecamatan Taktakan Kota Serang termasuk dalam usia produktif. Tingkat pendidikan yang dimiliki oleh responden dapat dikategorikan rendah karena jenjang pendidikan masih berada pada jenjang SMP dan SMA, namun tidak menjadi pengaruh untuk menjalankan agroindustri karena kegiatan dalam agroindustri ini cukup mudah dan tidak memerlukan keterampilan khusus.

Pengalaman kerja yang dimiliki oleh ketiga agroindustri cukup berbeda yaitu antara sembilan hingga dua puluh tahun pengalaman. Berdasarkan tingkat pengalaman menunjukkan bahwa ketiga agroindustri memiliki pengalaman yang cukup lama dalam mengolah melinjo menjadi produk emping dengan cara yang baik dan benar. Kapasitas produksi pada ketiga agroindustri cukup besar yaitu berkisar antara $857,5-1.400 \mathrm{~kg}$ per- 
bulan. Kapasitas tertinggi dapat dicapai oleh Agroindustri Kosim karena tenaga kerja pengrajin emping yang dimiliki oleh agroindustri tersebut lebih banyak dibandingkan dengan kedua agroindustri emping melinjo lainnya.

\section{Pengadaan Bahan Baku Agroindustri}

Bahan baku yang digunakan agroindustri emping adalah melinjo. Melinjo yang digunakan dalam proses produksi merupakan biji melinjo yang sudah tua. Produsen emping melinjo di Kecamatan Taktakan memperoleh bahan baku dari pengumpul langganan dan pasar sekitar Kecamatan Taktakan. Bahan baku melinjo juga diperoleh dari beberapa daerah yaitu Gunung Sari, Mancak, Pandeglang, dan Ciomas. Menurut Assauri (1999) pengadaan bahan baku harus sesuai dengan 6T, bahan baku tersebut harus sesuai dengan tepat waktu, tepat tempat, tepat jenis, tepat kualitas, tepat kuantitas, dan tepat harga.

\section{a. Waktu}

Ketiga agroindustri memiliki harapan dalam pengadaan bahan baku melinjo yaitu dilakukan selama setiap hari. Kenyataannya pengadaan bahan baku melinjo telah sesuai dengan harapan yaitu dilakukan setiap hari. Pengadaan bahan baku penunjang diharapkan dilakukan sekali dalam seminggu. Kenyataannya pengadaan bahan baku penunjang juga sama dilakukan selama sekali dalam seminggu. Bahan baku penunjang yang digunakan untuk memproduksi emping melinjo sangat mudah didapatkan, sehingga agroindustri tidak mendapat kendala terkait waktu dalam pengadaan bahan baku. Hal ini menunjukkan bahwa pengadaan bahan baku dan bahan baku penunjang pada ketiga agroindustri telah memenuhi komponen tepat waktu.

\section{b. Tempat}

Ketiga agroindustri emping melinjo sudah melakukan pembelian bahan baku pada tempat yang tepat. Agroindustri membeli melinjo ke pemasok langganan yang berada di sekitar Kecamatan Taktakan maupun di luar kecamatan. Meskipun pemasok dalam pengadaan bahan baku melinjo tidak dekat dengan ketiga lokasi agroindustri, namun selama ini tidak pernah ada kendala dalam pengadaan bahan baku yang ada. Semua bahan baku melinjo diantarkan langsung ke tempat agroindustri sesuai dengan skala produksi yang ada dan sesuai dengan kebutuhan. Bahan baku penunjang juga selalu tersedia secara cukup.
Agroindustri akan membeli sendiri bahan baku tersebut ke pemasok.

\section{c. Kualitas}

Kualitas bahan baku utama berupa biji melinjo yang digunakan pada agroindustri sudah tepat karena kualitas bahan baku sesuai dengan yang diharapkan. Kualitas kulit melinjo yang berwarna merah serta biji melinjo berwarna hitam. Bahan baku penunjang yang digunakan juga memiliki kualitas yang baik yang menunjang kegiatan produksi emping melinjo.

\section{d. Kuantitas}

Agroindustri Robiah dan Mulyati bahan baku melinjo tersedia dalam jumlah yang cukup sesuai kapasitas produksi dan sudah terpenuhi dengan baik yaitu 61,25-62,50 kg dalam sehari selama satu kali produksi, sedangkan pada Agroindustri Kosim jumlah bahan baku yang tersedia sering di bawah kapasitas produksinya yaitu hanya $100 \mathrm{~kg}$ per-hari sedangkan Agroindustri Kosim masih mampu memproduksi sebesar $250 \mathrm{~kg}$ melinjo. Jumlah bahan baku penunjang pada agroindustri Robiah dan Mulyati sudah terpenuhi dengan jumlah yang cukup sesuai dengan kebutuhan, sedangkan pada agroindustri kosim masih belum terpenuhi.

\section{e. Jenis}

Ketiga agroindustri menggunakan bahan baku melinjo lokal dari daerah sekitar Kecamatan Taktakan maupun di luar Kecamatan. Hal ini menunjukkan bahwa ketiga agroindustri emping melinjo mendukung penggunaan bahan baku lokal. Begitu pula dengan bahan baku penunjang yang digunakan adalah jenis bahan baku yang masih segar untuk digunakan dalam kegiatan produksi.

\section{f. Harga}

Harga yang diterima ketiga agroindustri emping melinjo dalam membeli bahan baku melinjo yaitu sebesar Rp12.000,00. Ketiga agroindustri memiliki harapan harga bahan baku melinjo terjangkau dan stabil namun kenyataan harga bahan baku melinjo fluktuatif. Hal ini disebabkan oleh ketersediaan bahan baku melinjo yang fluktiatif sedangkan permintaan pasar tinggi terutama saat hari raya. Saat hari raya harga bahan baku melinjo dapat mencapai Rp23.000,00/kg. Lain halnya dengan harga untuk bahan baku penunjang yang dibeli agroindustri cukup terjangkau. 


\section{Kinerja Produksi Agroindustri}

Kinerja produksi pada Agroindustri emping melinjo memiliki empat tipe pengukuran kinerja yaitu produktivitas, kapasitas, kualitas, dan kecepatan pengiriman (Prasetya dan Fitri 2009).

a. Produktivitas

Produktivitas adalah ukuran dalam mengkonversi input dari proses transformasi ke dalam output. Berdasarkan hasil perhitungan, rata- rata produktivitas tenaga kerja agroindustri emping melinjo pada Agroindustri Kosim, Agroindustri Robiah dan Agroindustri Mulyati antara output terhadap tenaga kerja masing-masing adalah sebesar 16,67 kg/HOK, 13,61 kg/HOK dan 16,67 $\mathrm{kg} / \mathrm{HOK}$ (Tabel 3). Hal ini berarti setiap satu HOK akan menghasilkan 16,67 kg emping melinjo pada Agroindusti Kosim, sedangkan pada agroindustri Robiah setiap satu HOK akan menghasilkan 13,61 kg emping melinjo dan Agroindustri Mulyati setiap satu HOK akan menghasilkan 16,67 kg emping melinjo.

\section{b. Kapasitas}

Kapasitas adalah suatu ukuran yang menyangkut kemampuan ouput dari suatu proses. Kapasitas agroindustri emping melinjo diperoleh dari actual ouput yaitu ouput berupa emping melinjo yang diproduksi dan design capacity yaitu kapasitas maksimal yang mampu dihasilkan agroindustri dalam memproduksi emping melinjo. Nilai kapasitas untuk ketiga agroindustri emping melinjo di Kecamatan Taktakan masing-masing adalah 0,20 atau 20 persen untuk Agroindustri Kosim, 0,61 atau 61 persen untuk Agroindustri Robiah dan 0,63 atau 63 persen Agroindustri Mulyati.

\section{c. Kualitas}

Berdasarkan hasil penelitian yang telah dilakukan, produk emping melinjo telah melalui proses penggorengan. Jenis uji pada ketiga agroindustri yang dapat terlihat dan dapat dirasakan yaitu bau, rasa, warna, dan penampakan yang terdapat pada produk emping melinjo semuanya normal.

Bau emping yang normal adalah bau khas melinjo, rasa khas melinjo, serta warna emping seperti warna melinjo dan penampakan melinjo yang bebas dari kulit ari dan benda asing lainnya. Agroindustri emping melinjo di Kecamatan Taktakan tidak pernah mencampurkan bahan tambahan, sehingga kualitas emping melinjo tetap terjaga dengan baik. Kualitas emping melinjo yang dihasilkan ketiga agroindustri belum mengacu pada standar SNI dalam memproduksi emping melinjo. Agroindustri ini juga belum melakukan jenis uji yang terdapat pada SNI 013712-1995 terkait syarat mutu emping melinjo.

\section{d. Kecepatan Pengiriman}

Berdasarkan hasil penelitian yang sudah dilakukan, untuk Agroindustri Mulyati pedagang datang sendiri untuk mengambil produknya. Jadi agroindustri jarang untuk mengantarkan produknya ke pelanggan sedangkan untuk Agroindustri Kosim dan Robiah melakukan pengiriman produk kepada pelanggan pada jarak tempuh lebih dari lima kilometer dengan waktu tempuh kurang dari 25-30 menit.

Kecepatan pengiriman pada dimensi pertama dikatakan baik, karena pelanggan tidak menunggu waktu yang lama dalam menerima produknya. Pengukuran kecepatan pengiriman pada dimensi kedua yaitu ketepatan pengiriman produk. Ketiga agroindustri emping melinjo melakukan jual beli produk emping melinjo untuk sampai ke pedagang besar tiga hari dalam seminggu dinilai sudah tepat, sehingga dimensi yang kedua dalam kecepatan pengiriman pada ketiga agroindustri emping melinjo tergolong sudah baik.

\section{Harga Pokok Produksi Agroindustri}

Perhitungan harga pokok produksi pada ketiga agroindustri emping melinjo di Kecamatan Taktakan menggunakan metode variable costing. Metode ini memperhitungkan semua biaya produksi yang terdiri dari biaya bahan baku, biaya tenaga kerja, dan biaya overhead pabrik baik tetap maupun variabel. Berdasarkan perhitungan yang telah dilakukan, ketiga agroindustri masih menerima keuntungan atau laba apabila didasarkan pada hasil perhitungan harga pokok produksi dengan metode variable costing karena harga jual yang ditetapkan berada diatas harga pokok produksi (Tabel 4).

Berdasarkan penelitian yang dilakukan Laisa, Sayekti dan Nugraha (2013), perhitungan harga pokok produksi ikan teri nasi kering pada musim angin Barat, Normal dan Timur berturut-turut yaitu sebesar Rp43.330,15, Rp34.269,58 dan Rp31.180,36. Harga jual yang berlaku sudah di atas harga pokok produksi sehingga memperoleh laba. Sama halnya dengan hasil perhitungan harga pokok produksi emping melinjo, bahwa harga jual yang berlaku sudah di atas harga pokok produksi sehingga pengolah memperoleh laba. 


\section{Bauran Pemasaran Emping Melinjo}

Pemasaran merupakan kegiatan ekonomi yang berfungsi menyampaikan barang atau jasa dari produsen ke konsumen. Salah satu cara yang dapat dilakukan dalam menyusun strategi pemasaran yang baik adalah dengan menggunakan bauran pemasaran. Menurut Kotler dan Keller (2009), komponen-komponen dari bauran pemasaran terdiri dari $4 \mathrm{P}$ yaitu product (produk), price (harga), place (lokasi atau distribusi), dan promotion (promosi).

\section{a. Produk (Product)}

Bentuk dan ukuran emping melinjo ketiga agroindustri ini tidak disesuaikan dengan permintaan konsumen. Hasil Penelitian ini sejalan dengan penelitian yang dilakukan oleh Shafira, Lestari, dan Affandi (2018) yang menjelaskan bahwa bentuk dan ukuran kerupuk bawang tidak sesuai dengan permintaan konsumen. Kemasan yang digunakan pada agroindustri emping melinjo berupa plastik pembungkus atau kantung plastik yang berukuran $10 \mathrm{~kg}$. Plastik pembungkus tersebut digunakan agar emping tetap renyah ketika sampai ke tangan konsumen.

Agroindustri Kosim telah mempunyai merek dagang, namun merek disediakan pemilik hanya kepada konsumen akhir yang membeli langsung pada agroindustri emping melinjo. Kualitas emping melinjo tersebut renyah dan memiliki rasa khas melinjo. Emping melinjo cenderung memiki keawetan yang cukup lama yaitu dua sampai tiga bulan.

\section{b. Harga (Price)}

Harga bahan baku melinjo akan memengaruhi harga jual dari produk emping melinjo. Hasil penelitian ini sejalan dengan penelitian yang dilakukan oleh Putri, Affandi, dan Nikmatullah (2020) yang menjelaskan harga yang ditawarkan produsen kepada konsumen sudah terjangkau dan sesuai dengan produk yang ditawarkan. Harga kopi bubuk Cap Jempol sebesar Rp50.000,00/kg dan cara pembayaran kopi bubuk Cap Jempol dilakukan secara tunai. Harga per $\mathrm{kg}$ produk emping melinjo Agroindustri Kosim, Agroindustri Robiah dan Mulyati harga dibandrol sebesar Rp45.000,00.
Tabel 4. Harga pokok produksi emping melinjo agroindustri Kecamatan Taktakan

\begin{tabular}{cccc}
\hline Keterangan & $\begin{array}{c}\text { Agro } \\
\text { industri } \\
\text { Kosim }\end{array}$ & $\begin{array}{c}\text { Agro } \\
\text { industri } \\
\text { Robiah }\end{array}$ & $\begin{array}{c}\text { Agro } \\
\text { industri } \\
\text { Mulyati }\end{array}$ \\
\hline $\begin{array}{c}\text { Harga } \\
\text { pokok } \\
\text { produksi } \\
(\mathrm{kg})\end{array}$ & $32.039,85$ & $35.074,12$ & $33.296,03$ \\
$\begin{array}{c}\text { Harga jual } \\
(\mathrm{Rp} / \mathrm{kg})\end{array}$ & $45.000,00$ & $45.000,00$ & $45.000,00$ \\
\hline
\end{tabular}

c. Tempat atau distribusi (Place)

Lokasi ketiga agroindustri emping melinjo belum tergolong strategis karena berada di dalam jalan gang sehingga konsumen yang baru terkadang kesulitan menemukan lokasi agroindustri. Akan tetapi walaupun lokasi berada di dalam gang, sudah dapat dilalui dengan mudah oleh transportasi motor maupun mobil bagi para konsumen yang ingin membeli produk. Berdasarkan komponen tempat pemasaran tiga agroindustri emping melinjo menjual produknya di rumah produksi dengan menjual langsung kepada konsumen, melalui pedagang besa atau pasar- pasar.

\section{d. Promosi (Promotion)}

Kegiatan promosi yang dilakukan oleh ketiga agroindustri emping melinjo di Kecamatan Taktakan masih sangat minim dan sederhana, melalui metode personal selling yaitu melakukan promosi dari mulut ke mulut ke beberapa kerabat dan teman, kemudian kerabat dan teman tersebut yang menyebarkan kepada masyarakat lain, selain itu hanya agroindustri emping melinjo Kosim yang menggunakan media promosi lain seperti mencantumkan nomor telepon agroindustri pada merek dagang sebagai media promosi. Penggunaan media promosi yang masih sangat minim dikarenakan keterbatasan pengetahuan yang dimiliki pemilik agroindustri, sehingga masih menjalankan seluruh kegiatan dengan cara konvensional.

\section{Keberlanjutan Agroindustri Emping Melinjo}

Keberlanjutan adalah kondisi yang akan dihadapi oleh suatu usaha dimasa yang akan datang baik kecendrungan untuk meningkatkan atau memberhentikannya. Menurut Trimo, Hidayat dan 
Budiman (2019) terdapat beberapa faktor penentu keberlanjutan usaha agroindustri yaitu faktor internal yang terdiri dari kondisi organisasi, kemampuan mesin olah dan faktor eksternal yang terdiri dari permintaan pasar, ketersediaan bahan baku melinjo dan pesaing.

\section{a. Faktor Internal}

Sumber daya manusia yang terdapat pada masingmasing agroindustri di Kecamatan Taktakan terdiri dari pemilik dan tenaga kerja harian yang bertugas sebagai pengrajin emping melinjo. Agroindustri Kosim sumber daya manusia terdiri dari pemilik yaitu Bapak Kosim dengan delapan tenaga kerja harian yang membantu selama proses produksi, agroindustri Robiah terdiri dari pemilik yaitu Ibu Robiah dengan jumlah tenaga kerja harian sebanyak enam orang dan agroindustri Mulyati yang terdiri dari pemilik yaitu Ibu Mulyati dengan lima orang tenaga kerja harian.

Waktu kerja setiap pekerja mulai pukul 07.00 WIB hingga pukul 13.00 WIB. Upah yang diberikan kepada tenaga kerja adalah upah harian. Namun, kegiatan pengolahan emping melinjo belum berpegangan pada SOP yang merupakan panduan pelaksanaan.

Ketersediaan mesin olah tentunya akan membantu meningkatkan produksi atau memudahkan pekerjaan yang berkaitan dengan produksi. Namun, pada agroindustri emping melinjo di Kecamatan Taktakan masih dilakukan dengan cara manual dan alat-alat yang masih sangat tradisional. Proses pembuatan emping yang masih tradisional secara turun temurun namun kinerja dari pengrajin emping melinjo dapat dikatakan baik. Hal ini dibuktikan dengan hasil kapasistas produksi yang bernilai baik sehingga proses produksi emping melinjo masih dapat berlangsung tanpa adanya kendala dalam produksi emping melinjo.

\section{b. Faktor Eksternal}

Permintaan pasar akan produk emping melinjo cukup tinggi mengingat bahwa emping melinjo merupakan salah satu oleh-oleh khas Kota Serang. Konsumen emping melinjo cukup banyak dikarenakan emping melinjo sangat dibutuhkan di berbagai tempat khususnya rumah makan atau toko oleh-oleh.

Emping melinjo berguna sebagai makanan pelengkap di restoran kecil hingga besar. Selain itu, banyak masyarakat dari berbagai daerah membutuhkan emping melinjo dengan jumah yang cukup besar, seperti pada acara-acara tertentu atau pada saat hari raya. Memanfaatkan peluang permintaan pada waktu-waktu tertentu dapat meningkatkan pemasaran agroindustri emping melinjo di Kecamatan Taktakan. Agroindustri emping melinjo di Kecamatan Taktakan memiliki pemasok atau pengumpul langganan yang memenuhi kebutuhan bahan baku melinjo setiap harinya. Bahan baku melinjo diperoleh dari petani melinjo di berbagai daerah dari dalam kota yaitu, Gunung Putri, Ciomas, dan Mancak maupun luar kota seperti Pandeglang. Berdasarkan hasil penelitian, agroindustri beroperasi selama satu bulan lamanya di bulan Maret, produksi tetap dilakukan tanpa adanya kekurangan pasokan bahan baku. Kondisi ini menunjukkan bahwa prospek yang dimiliki oleh agroindustri emping melinjo saat ini cukup baik karena ketersediaan bahan bahan baku melinjo saat ini masih cukup, namun ke depan untuk menjamin ketersediaan bahan baku melinjo perlu didorong adanya aspek budidaya yaitu penanaman kembali tanaman baru.

Selain Kecamatan Taktakan, Kabupaten Pandeglang merupakan sentra agroindustri pengrajin emping melinjo yang cukup terkenal. Para produsen yang selalu tepat memenuhi permintaan pasar dan dengan produk emping melinjo yang berkualitas akan mudah dalam mendapatkan pelanggan tetap untuk bermitra bahkan mendapat supplier tetap dengan mudah. Daerah pemasaran agroindustri emping melinjo antara lain Cilegon, Kemang, Keramat, Citra Gading, Terminal Pakupatan, dan pasar sekitar Kota Serang. Berdasarkan hasil penelitian agroindustri emping melinjo telah memiliki pelanggan tetap meskipun daerah pemasaran emping melinjo masih sangat sempit dibandingkan dengan agroindustri sejenis lainnya. Hasil penelitian ini menunjukan bahwa keberlanjutan agroindustri emping melinjo memiliki prospek yang cukup baik.

\section{KESIMPULAN}

Pengadaan bahan baku melinjo pada agroindustri emping melinjo di Kecamatan Taktakan belum sesuai dengan kriteria enam tepat yaitu tepat kuantitas dan tepat harga. Kinerja produksi pada agroindustri emping melinjo sudah cukup baik meskipun pada komponen fleksibilitas masih belum terpenuhi. Penetapan harga pokok produksi pada agroindustri emping melinjo menggunakan metode full costing telah menguntungkan. Penerapan strategi pemasaran berupa bauran 
pemasaran $4 \mathrm{P}$ pada agroindustri emping melinjo telah diterapkan cukup baik meskipun perlu beberapa peningkatan pada beberapa aspek seperti promosi. Keberlanjutan agroindustri emping melinjo di Kecamatan Taktakan cukup baik yaitu pada faktor eksternal.

\section{DAFTAR PUSTAKA}

Arikunto S. 2002. Metodologi Penelitian. PT. Rineka Cipta. Jakarta.

Assauri S. 1999. Manajemen Produksi dan Operasi, Edisi Revisi. LPFE-UI. Jakarta.

Departemen Perindustrian dan Perdagangan. 1995. Standar Mutu Emping (SNI 01-3712-1995). Jakarta. https://maharani2015.files. wordpress.com/2015/07/deputi_bsn.pdf. [20 Oktober 2018].

Dinas Perindustrian, Perdagangan dan Koperasi Kota Serang. 2018. Usaha Pengolahan Emping Melinjo Di Kecamatan Taktakan Kota Serang Tahun 2018. Kota Serang.

Dinas Pertanian Tanaman Pangan dan Horikultura Provinsi Banten. 2017. Produksi Tanaman Buah-Buahan dan Sayuran Tahunan Menurut Jenis Tanaman di Provinsi Banten. Banten. www.banten.bps.go.id. [14 Oktober 2018].

Kotler P dan K.L. Keller. 2009. Manajemen Pemasaran. Erlangga. Jakarta. https://thidiweb.com/bauran-pemasaran/. [10 Oktober 2018].

Laisa DD, Sayekti WD, dan Nugraha A. 2013. Analisis harga pokok produksi dan strategi pengembangan industri pengolahan ikan teri nasi kering di Pulau Pasaran Kecamatan Teluk Betung Barat Kota Bandar Lampung. Jurnal Ilmu Ilmu Agribisnis, 1(2): 111-117. https://jurnal.fp.unila.ac .id/index.php/JIA/article/view/237/236. Juni 2020].

Ledy DS, Haryono D, dan Situmorang S. 2019. Analisis bauran pemasaran (marketing mix)dan strategi pengembangan (studi kasus pada agroindustry kopi bubuk cap intan di
Kota Bandar Lampung). Jurnal Ilmu Ilmu Agribisnis, $\quad 7(1)$ : 52-59. http://jurnal.fp.unila.ac.id/index.php/JIA/articl e/view/3331/2552. [12 Februari 2020].

Mulyadi. 1991. Akuntansi Biaya. BPFE. Yogyakarta.

Prasetya H dan Fitri L. 2009. Manajemen Operasi. Media Pressindo. Yogyakarta. https://media.neliti.com/media/publications/13 321-ID-kinerja-produksi-dan-nilaitambahagroindustri-emping-melinjo-di-kotabandarlam.pdf. [16 Mei 2019].

Putri RM, Haryono D, dan Nugraha A. 2019. Analisis kinerja dan lingkungan ekternal agroindustri keripik pisang (studi kasus di Desa Sungai Langka Kabupaten Pesawaran). Jurnal Ilmu Ilmu Agribisnis, 7(2): 203-210. http://jurnal.fp.unila.ac.

id/index.php/JIA/article/view/3382/2583 . [12 Februari 2020].

Putri VD, Affandi MI, Nikmatullah D. 2020. Analisis kepuasan konsumen bauran dan pemasaran pada agroindustri kopi bubuk Cap Jempol di Kota Bandar Lampung. Jurnal Ilmu Ilmu Agribisnis, 8(1): 131-135. https://jurnal.fp.unila.ac.id/ index.php/JIA/article/view/4001/2911. Juni 2020].

Shafira F, Lestari DAH, dan Affandi MI. 2018. Analisis keragaan agroindustri tahu kulit di Kelurahan Gunung Sulah Kecamatan Way Halim Kota Bandar Lampung. Jurnal Ilmu Ilmu Agribisnis, 6(3): 279-287. http://jurnal.fp.unila.ac.id /Index. php/JIA/article/view/3025/2414. [12 Februari 2020].

Trimo L, Hidayat S, dan Budiman MA. 2019. Beberapa Faktor Penentu Keberlanjutan Usaha Agroindustri Teh Rakyat. Jurnal Pemikiran Masyarakat Ilmiah Berwawasan Agribisnis, $\quad$ 5(1). 46-59. https://jurnal.unigal.ac.id/index.php/mimbarag ribisnis/article/view/1630. [20 Mei 2019]. 